\title{
Removal of radio $N$-nitrosodimethylamine (NDMA) from drinking water by coagulation and Powdered Activated Carbon (PAC) adsorption
}

\author{
J. Chung ${ }^{1}$, Y. Yoon ${ }^{2}$, M. Kim ${ }^{3}$, S.-B. Lee ${ }^{3}$, H.-J. Kim ${ }^{3}$, and C.-K. Choi ${ }^{3}$ \\ ${ }^{1}$ R\&D Center, Samsung Engineering Co. Ltd., 415-10 Woncheon-Dong, Youngtong-Gu, Suwon, Gyeonggi-Do, \\ 443-823, Korea \\ ${ }^{2}$ Department of Civil and Environmental Engineering, University of South Carolina, Columbia, SC 29208, USA \\ ${ }^{3}$ Department of Civil and Environmental System Engineering, Hanyang University, 1271 Sa-1 Dong, Ansan, \\ Gyeonggi-Do, 425-791, Korea
}

Received: 17 March 2009 - Published in Drink. Water Eng. Sci. Discuss.: 31 March 2009

Revised: 31 July 2009 - Accepted: 1 August 2009 - Published: 5 October 2009

\begin{abstract}
The presence of $N$-nitrosodimethylamine (NDMA) in drinking water supplies has raised concern over its removal by common drinking water treatment processes. However, only limited studies have been examined to evaluate the potential removal of NDMA by numerous water treatment technologies within a realistic range (i.e., sub $\mu \mathrm{g} / \mathrm{L}$ ) of NDMA levels in natural water due to analytical availability. In this study, a simple detection method based on scintillation spectroscopy has been used to quantify the concentration of ${ }^{14} \mathrm{C}$-labeled NDMA at various ratios of sample to scintillation liquid. Without sample pretreatment, the method detection limits are $0.91,0.98,1.23$, and $1.45 \mathrm{ng} / \mathrm{L}$ of NDMA at scintillation intensity ratios of 10:10, 5:15, 15:5, and 2.5:17.5 (sample: scintillation liquid), respectively. The scintillation intensity in all cases is linear $\left(R^{2}>0.99\right)$ and is in the range of 0 to $100 \mathrm{ng} / \mathrm{L}$ of NDMA. In addition, because scintillation intensity is independent of solution $\mathrm{pH}$, conductivity, and background electrolyte ion types, a separate calibration curve is unnecessary for NDMA samples at different solution conditions. Bench-scale experiments were performed to simulate individual treatment processes, which include coagulation and adsorption by powdered activated carbon (PAC), as used in a drinking water treatment plant, and biosorption, a technique used in biological treatment of waste water. The results show that coagulation and biosorption may not be appropriate mechanisms to remove NDMA (i.e., hydrophilic based on its low octanol-water partitioning coefficient, $\log K_{o w}=0.57$ ). However, relatively high removal of NDMA (approximately 50\%) was obtained by PAC at high PAC dosages and longer contact times.
\end{abstract}

\section{Introduction}

$N$-nitrosodimethylamine (NDMA) is a toxic and carcinogenic yellow liquid that has been identified as a contaminant in drinking water, ground water, and a variety of other matrices (NRC, 1981; Leoppky and Micheljda, 1994; Mitch and Sedlak, 2004). One factor for the seemingly increasing levels of NDMA is directly related to the increasing sophistication of NDMA analysis. Since the late 1990s, a large number of studies have developed and improved NDMA analy-

Correspondence to: M. Kim (moonilkim@ hanyang.ac.kr) sis. Currently, several jurisdictions have implemented regulations that require widespread measurement of NDMA in raw and drinking watersuch regulations led to the identification of a higher occurrence of NDMA in water than was expected. Although NDMA is listed as a priority pollutant in the United States (CFR, 2001), a federal maximum contaminant level has not been established for drinking water. However, the Ontario Ministry of the Environment and Energy established an Interim Maximum Acceptable Concentration of $9 \mathrm{ng} / \mathrm{L}$ for NDMA in drinking water (MOE, 2000). In addition, after noticing the prevalence of NDMA, the California Department of Health Services has established an interim action level of $20 \mathrm{ng} / \mathrm{L}$, which was later reduced to $10 \mathrm{ng} / \mathrm{L}$ (DHS, 2002). 
Despite the increasing concern about the adverse effect of NDMA, conventional water treatment technologies may not effectively remove NDMA. NDMA is a semi-volatile, polar organic chemical, and a highly water-soluble compound (Chemfinder, 2003). Separate studies have shown that high concentration NDMA sorbs poorly to granular activated carbon (GAC) or soil at low GAC dosages (Kaplan and Kaplan, 1985; Gumnison et al., 2000). In addition, although there is little information regarding the potential for biological removal of NDMA, NDMA is somewhat resistant to biodegradation and is difficult to remove by air stripping and ozonation (Holgnè and Bader, 1983; Siddiqui and Atasi, 2001). Iron oxides can be used to reduce NDMA to dimethylamine (DMA) and ammonia; however, due to the slow kinetics of the reaction, this treatment method is not cost effective. Although several previous studies investigated NDMA removal using drinking water treatment technologies (Kaplan and Kaplan, 1985; Gumnison et al., 2000; Holgnè and Bader, 1983; Siddiqui and Atasi, 2001), only high initial concentrations $(>1000 \mathrm{ng} / \mathrm{L})$ were tested. However, since NDMA is frequently found at extremely low concentrations (parts per trillion, ppt; $\mathrm{ng} / \mathrm{L}$ ) in water supplies and wastewater effluents, there remain issues regarding NDMA removal at low initial concentrations from natural waters containing natural organic matter (NOM) and ions.

In order to evaluate the potential removal of NDMA by numerous water treatment technologies within a realistic range of NDMA levels in natural water, an important goal now is to be able to detect NDMA at ultra-trace levels. Analytical determination of NDMA content from surface water and wastewater commonly involves the use of gas chromatography-mass spectrometry (GC-MS or MS/MS) with chemical ionization, or traditional electron impact with continuous liquid-liquid extraction, solid phase extraction, or solid phase microextraction for ppt level NDMA analysis (Yoo et al., 2000; Mitch et al., 2003; Eaton and Briggs, 2000). However, these analytical techniques have issues regarding pretreatment requirements, compound recoveries, and detection limits. In addition, these techniques are expensive, time consuming, and require a high degree of analytical knowledge.

Less complex analytical approaches may be more suitable for lab process studiesone approach is using a liquid scintillation counter for measuring radio-labeled NDMA. Previous studies used ${ }^{14} \mathrm{C}$-labeled NDMA for NDMA removal studies from water and soil (Fleming et al., 1996; Gumnison et al., 2000). In these studies, raw water and soil-water mixtures were spiked to initial NDMA concentrations of $1000 \mathrm{ng} / \mathrm{L}$ and $5000 \mathrm{ng} / \mathrm{L}$, respectively. In addition, a liquid scintillation counter was used to determine relatively high concentrations of ${ }^{14} \mathrm{C}$-labeled NDMA ( $\left.>100 \mathrm{ng} / \mathrm{L}\right)$. However, it was still unclear how the method detection limits (MDL) were determined in terms of the ratio of sample to scintillation liquid and counting time.
To our knowledge, only limited research on NDMA removal using conventional and/or advanced water treatment technologies has been conducted at low NDMA initial concentrations. Therefore, in this study, several water treatment technologies including coagulation and powdered activated carbon (PAC) adsorption were tested to evaluate the potential of ${ }^{14} \mathrm{C}$-labeled NDMA removal at extremely low NDMA initial concentrations $\left(C_{o}=100 \mathrm{ng} / \mathrm{L}\right)$. In addition, biosorption experiments were conducted using conventional activated sludge to investigate NDMA removal. For this study, a simple analytical technique for rapid determination of a ${ }^{14} \mathrm{C}$-labeled NDMA was developed using a liquid scintillation counter. We have also demonstrated role of scintillation counting for process studies with emerging contaminant available from pharmacological studies.

\section{Materials and methods}

\subsection{Water sources}

Two water sources, Ultrapure (natural organic matter (NOM) free) water prepared from water purification system (DirectQ 3 system, Millipore, Korea) and raw drinking water (RDW) collected from a local water treatment plant (WTP), were selected for this study. The characteristics of the water sources used in this study are described in Table 1 . An NDMA solution $\left(C_{o}=100 \mathrm{ng} / \mathrm{L}\right)$ was added to Ultrapure water in the presence of $\mathrm{NaCl}, \mathrm{Na}_{2} \mathrm{SO}_{4}$, or $\mathrm{CaCl}_{2}$ to generate various conductivity values $(30,60$, and $120 \mathrm{mS} / \mathrm{m})$; the $\mathrm{pH}$ was adjusted to $4.5,7$, or $9( \pm 0.1)$ using $\mathrm{HCl}$ and/or $\mathrm{NaOH}$ solutions in the presence of $\mathrm{NaCl}$. The NDMA sample was buffered by adding a $1 \mathrm{M}$ phosphate buffer solution to the sample to create a $1 \mathrm{mM}$ buffer concentration. In separate experiments, NDMA was added to RDW at a concentration of $100 \mathrm{ng} / \mathrm{L}$.

RDW, collected from a local WTP, was used for the evaluation of NDMA removal from water. NDMA was spiked into raw water without filtration for aluminum sulfate (alum), ferric chloride, and ferric sulfate. The source water was filtered using a $1.2 \mu \mathrm{m}\left(47 \mathrm{~mm}\right.$ GF/C) glass-fiber filter (Whatman ${ }^{\circledR}$ International Ltd., Maidstone, England) to remove particulate matter prior to spiking in NDMA for PAC experiments. Control samples containing NDMA spikes in both filtered and nonfiltered water were prepared in at least triplicate.

\subsection{NDMA determination by scintillation counter}

${ }^{14} \mathrm{C}$-labeled NDMA was purchased from American Radiolabeled Chemicals (St. Louis, MO, USA) with an activity of 16.8 millicuries $(\mathrm{mCi}) / \mathrm{mmol}$ in deionized water. This concentration corresponds to $134.7 \mathrm{mg} / \mathrm{L}$ of NDMA. Stock solutions were initially prepared in Ultrapure water at $10000 \mathrm{ng} / \mathrm{L}$ of NDMA and were subsequently diluted with Ultrapure water to different concentrations of $1,5,10,25,50$, 
Table 1. Characteristics of source waters.

\begin{tabular}{lcccc}
\hline Source water & $\begin{array}{c}\text { DOC } \\
(\mathrm{mg} / \mathrm{L})\end{array}$ & $\begin{array}{c}\text { Conductivity } \\
(\mathrm{mS} / \mathrm{m})\end{array}$ & $\mathrm{pH}$ & $\begin{array}{c}\text { NDMA } \\
(\mathrm{ng} / \mathrm{L})\end{array}$ \\
\hline Ultrapure water & $<0.2$ & $<0.5,30,60$, and $120^{\mathrm{a}}$ & $4.5,7.0$, and 9.0 & 100 \\
WTP raw water & 2.4 & 13.7 & 7.1 & 100 \\
\hline
\end{tabular}

${ }^{\text {a }}$ Conductivity was adjusted by adding $\mathrm{NaCl}, \mathrm{Na}_{2} \mathrm{SO}_{4}$, and/or $\mathrm{CaCl}_{2}$ solution after $\mathrm{pH}$ was buffered by a phosphoric solution.

75 , and $100 \mathrm{ng} / \mathrm{L}$ for the calibration run. NDMA radioactivity was determined using a liquid scintillation counter (GMI, Beckman LS6500, Albertville, MN, USA). For scintillation measurements, various ratios of sample to scintillation liquid (ScintiSafe Plus 50\%, Fisher Scientific, USA) were tested at 2.5:17.5, 5:15, 10:10, and 15:5. Scintillation liquid was pipetted into a standard glass vial and the sample was added to a total target volume of $20 \mathrm{~mL}$. NDMA quantifications were conducted at various counting times of 1,5 , and 10 minutes (min). The scintillation liquid with Ultrapure water or RDW alone was used to measure background radiation. The effect of inorganic salts and NOM in RDW on NDMA radioactivity was also determined.

Dissolved organic carbon (DOC) was measured using a combustion/non-dispersive infrared gas analysis method (Shimadzu Model TOC-5050A). The natural water sourcewas prefiltered using a $1.2-\mu \mathrm{m}(47 \mathrm{~mm} \mathrm{GF} / \mathrm{C})$ ashed glassfiber filter (Whatman ${ }^{\circledR}$ International Ltd.) prior to use.

\subsection{Coagulation and PAC adsorption experiments}

Coagulation and PAC adsorption experiments were conducted as jar tests using a six-place gang stirrer (Phipps and Bird, Richmond, VA, USA); jars were $2 \mathrm{~L}$ glass beakers filled with $1.5 \mathrm{~L}$ of NDMA-spiked water. Chemicals (see below) were added via pipette during a rapid mixing step. Mixing conditions were $2 \mathrm{~min}$ of rapid mixing at $100 \mathrm{rpm}, 20 \mathrm{~min}$ flocculation at $30 \mathrm{rpm}$, and $60 \mathrm{~min}$ of settling time (no mixing).

Three coagulants, aluminum sulfate, ferric chloride, and ferric sulfate (Fisher Scientific, USA), were used for jar tests to simulate coagulation, flocculation, and settling. Doses for each coagulant $(3,6$, and $12 \mathrm{mg} / \mathrm{L})$ were selected based upon an initial estimate of total organic carbon (TOC) concentration. All chemical dosages for individual experiments are summarized in Table 2.

One PAC, 6H (Coal-based, Junsei Chemical Co., Ltd., Saitama, Japan), was used to stimulate adsorption. PAC was hydrated in stock solutions ( 10 or $1000 \mathrm{mg} / \mathrm{L}$ ) for 24 hours (h) in Ultrapure water prior to use and added as a slurry to the samples. Applied PAC doses ranged from 1 to $50 \mathrm{mg} / \mathrm{L}$. NDMA was contacted with PAC at an initial concentration of $100 \mathrm{ng} / \mathrm{L}$. Table 2 summarizes PAC doses and contact times. Additional experiments were also conducted
Table 2. Water quality and dosages of the experiments.

\begin{tabular}{ll}
\hline Parameter & Value \\
\hline $\begin{array}{l}\text { Coagulation experiment } \\
\text { Initial } \mathrm{pH}\end{array}$ & 7.1 \\
Dosages $[\mathrm{mg} / \mathrm{L}]$ & 3,6 , and 12 \\
& \\
Adsorption experiment & $6 \mathrm{H}$ \\
PAC brand & $1,2,4,6,8,10,25$, and $50 \mathrm{mg} / \mathrm{L}$ \\
PAC dosages $[\mathrm{mg} / \mathrm{L}]$ & for 1,4, and $24 \mathrm{~h}$ \\
& $50,100,200,250$, and $300 \mathrm{mg} / \mathrm{L}$ \\
& for $1 \mathrm{~h}$ \\
& \\
Biosorption experiment & \\
MLSS concentrations & $0.5-10 \mathrm{~g} / \mathrm{L}$ \\
\hline
\end{tabular}

with RDW with PAC at initial concentrations ranging from $50 \mathrm{mg} / \mathrm{L}$ to $300 \mathrm{mg} / \mathrm{L}$ for contact times of 5,20 , and $60 \mathrm{~h}$. RDW was spiked with an NDMA concentration of $100 \mathrm{ng} / \mathrm{L}$.

\subsection{Biosorption experiments}

The biosorption experiment was performed using activated sludge taken from a municipal wastewater plant (Ansan, Korea). The biosorption experiment was conducted in an Erlenmeyer flask $(500 \mathrm{~mL})$ containing a $100 \mathrm{~mL}$ NDMA solution at $20^{\circ} \mathrm{C}$. The $1 \mathrm{M}$ phosphate buffered NDMA solution was adjusted to a pH of 7.0 with $\mathrm{H}_{2} \mathrm{SO}_{4}$ and $\mathrm{NaOH}$ solutions, and a small quantity $(0.05 \mathrm{~g} / \mathrm{L})$ of glucose was added to the flask for maintenance of the cells. A weighed amount of the resting cells $(4.5 \mathrm{~g} / \mathrm{L}$, based on dry weight) was added to the flask containing the NDMA solution of known NDMA concentration. The flask was incubated in a shaker at $150 \mathrm{rpm}$ for $24 \mathrm{~h}$. Periodically, samples were withdrawn and centrifuged at $5000 \mathrm{rpm}$ for $5 \mathrm{~min}$. The supernatant was analyzed for residual NDMA. All biosorption experiments were conducted in a similar manner to study the effect of biomass concentration $(0.5-10.0 \mathrm{~g} / \mathrm{L})$ on changes in NDMA concentrations $(10-1000 \mathrm{ng} / \mathrm{L})$. All experiments were performed in triplicate. 


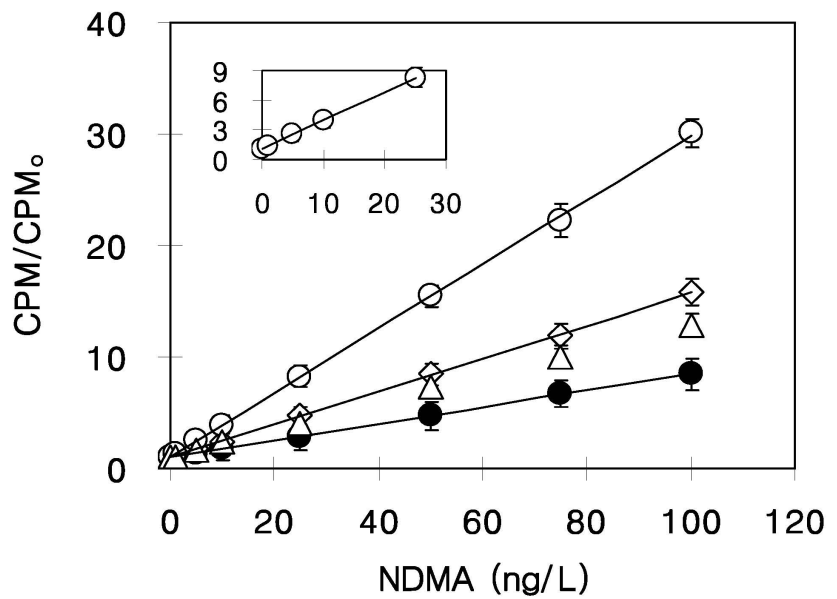

Figure 1. Dependence of scintillation intensity on the ${ }^{14} \mathrm{C}$-labeled NDMA concentration at $\mathrm{pH} 4.5$, conductivity $\leq 0.5 \mathrm{mS} / \mathrm{m}$, and CT $=10 \mathrm{~min}$. $\bullet$ sample $/$ scintillation liquid ratio $=2.5: 17.5 ; \diamond$ sample/scintillation liquid ratio $=5: 15 ; \circ$ sample/scintillation liquid ratio $=10: 10 ; \Delta$ sample/scintillation liquid ratio $=15: 5$. CPM is the measured scintillation intensity at [NDMA], and $\mathrm{CPM}_{0}(39 \pm 1.9)$ is the scintillation intensity at the reference condition (zero NDMA). The insert shows the detail at low concentrations for NDMA.

\section{Results and discussion}

\subsection{NDMA determination by scintillation counter}

The scintillation intensities of ${ }^{14} \mathrm{C}$-labeled NDMA was measured by a scintillation counter at $\mathrm{pH} 4.5$ and at a conductivity of $<0.5 \mathrm{mS} / \mathrm{m}$; these intensity values are presented in Fig. 1. All measurements were performed at a counting time of $10 \mathrm{~min}$ and at room temperature $\left(20 \pm 1^{\circ} \mathrm{C}\right)$. Counts per minute (CPM) is commonly used to describe radiation intensity. Due to potential instrument-to-instrument variations, the intensities are normalized by the reference intensity, $\mathrm{CPM}_{0}(39 \pm 1.9)$, for a zero concentration of NDMA.

Scintillation intensity varies depending on the ratio of sample to scintillation liquid. The order of scintillation intensity is 10:10 $>5: 15>15: 5>2.5: 17.5$ for NDMA. The scintillation intensity in all cases is clearly linear $\left(R^{2}>0.99\right)$ in the range of 0 to $100 \mathrm{ng} / \mathrm{L}$ of NDMA. The insert in Fig. 1 shows that the relationship is linear even for very low concentrations with a 10:10 ratio, indicating the robustness of the technique. Furthermore, because the scintillation intensity at $100 \mathrm{ng} / \mathrm{L}$ NDMA is nearly 9 (2.5:17.5), 13 (15:5), 16 $(5: 15)$, and $30(10: 10)$ times the intensity for zero concentration, this technique demonstrates a wide dynamic range. MDLs were determined using a $5 \mathrm{ng} / \mathrm{L}$ NDMA solution of all ratios of sample to scintillation liquid.

The experiments were repeated eight times and the MDL was calculated based upon the standard deviation (c.v. $\leq 3 \%$ ) of the replicate measurements. This calculation follows the United States Environmental Protection Agency MDL method (Revision 1.1) (Behymer et al., 1993). MDLs are

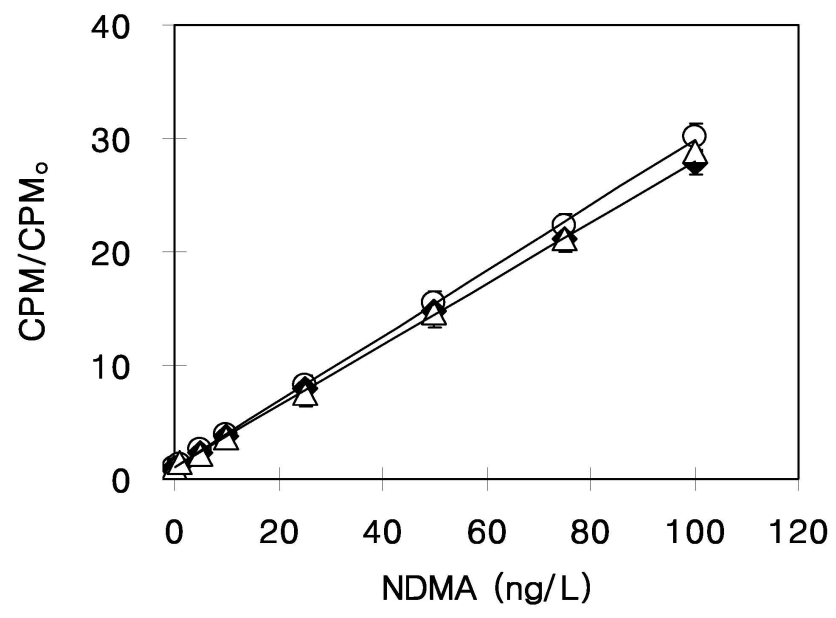

Figure 2. Dependence of scintillation intensity on the ${ }^{14} \mathrm{C}$-labeled NDMA concentration at various counting times. $\mathrm{pH} 4.5$; conductivity $<0.5 \mathrm{mS} / \mathrm{m}$; sample/scintillation liquid ratio $=10: 10 . \Delta \mathrm{CT}=$

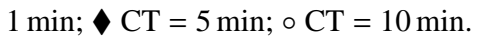

$0.91,0.98,1.23$, and $1.45 \mathrm{ng} / \mathrm{L}$ of NDMA for 10:10, 5:15, 15:5, and 2.5:17.5 ratios, respectively, without any pretreatment or preconcentration. In some cases, error bars based on standard deviation calculated from triplicates of scintillation intensity measurements are smaller than the graph points in the figure.

The scintillation intensities for ${ }^{14} \mathrm{C}$-labeled NDMA measured at various counting times $(\mathrm{CTs}=1,5$, and $10 \mathrm{~min}$ ) are presented in Fig. 2 at various concentrations $(0$ to $100 \mathrm{ng} / \mathrm{L}$ ). The differences between the scintillation intensity are negligible for CTs of 1 and $5 \mathrm{~min}$. However, increasing the CT from 5 to $10 \mathrm{~min}$ results in a slight increase $\left(\mathrm{CPM} / \mathrm{CPM}_{0}=27.9\right.$ for $5 \mathrm{~min}$ and $\mathrm{CPM} / \mathrm{CPM}_{0}=30.1$ for $10 \mathrm{~min}$ ) in the scintillation intensity. Although it is unclear how the optimal CT was determined, a previous study also recommended a $10 \mathrm{~min} \mathrm{CT}$ for ${ }^{3} \mathrm{H}$-labeled $17-\beta$ estradiol determination (Fuerhacker et al., 2001).

The dependence of scintillation intensities of the ${ }^{14} \mathrm{C}$ labeled NDMA on various conductivities $(30,60$, and $120 \mathrm{mS} / \mathrm{m}$ with $\mathrm{NaCl}$ at $\mathrm{pH} 7), \mathrm{pH}(4.5,7$, and 9 at a conductivity of $60 \mathrm{mS} / \mathrm{m}$ with $\mathrm{NaCl}$ ), and electrolyte salt type $\left(\mathrm{NaCl}, \mathrm{Na}_{2} \mathrm{SO}_{4}\right.$, and $\mathrm{CaCl}_{2}$ at $\mathrm{pH} 7$ and at a conductivity of $60 \mathrm{mS} / \mathrm{m}$ ) is shown in Fig. 3 for a single NDMA concentration of $100 \mathrm{ng} / \mathrm{L}$. Although the phosphate buffer is commonly effective in a pH range of 5 to 8 (Perrin and Dempsey, 1974), all $\mathrm{pH}$ values remained consistent over the entire range. The scintillation intensity of NDMA remained constant regardless of conductivity and $\mathrm{pH}$ levels, and electrolyte salt types. In addition, although the RDW contained DOC $(2.4 \mathrm{mg} / \mathrm{L})$ and various anions and cations (with a conductivity of $13.7 \mathrm{mS} / \mathrm{m}$ ), the differences between the scintillation intensities are negligible. These results are consistent with previous studies that show that scintillation intensity is 

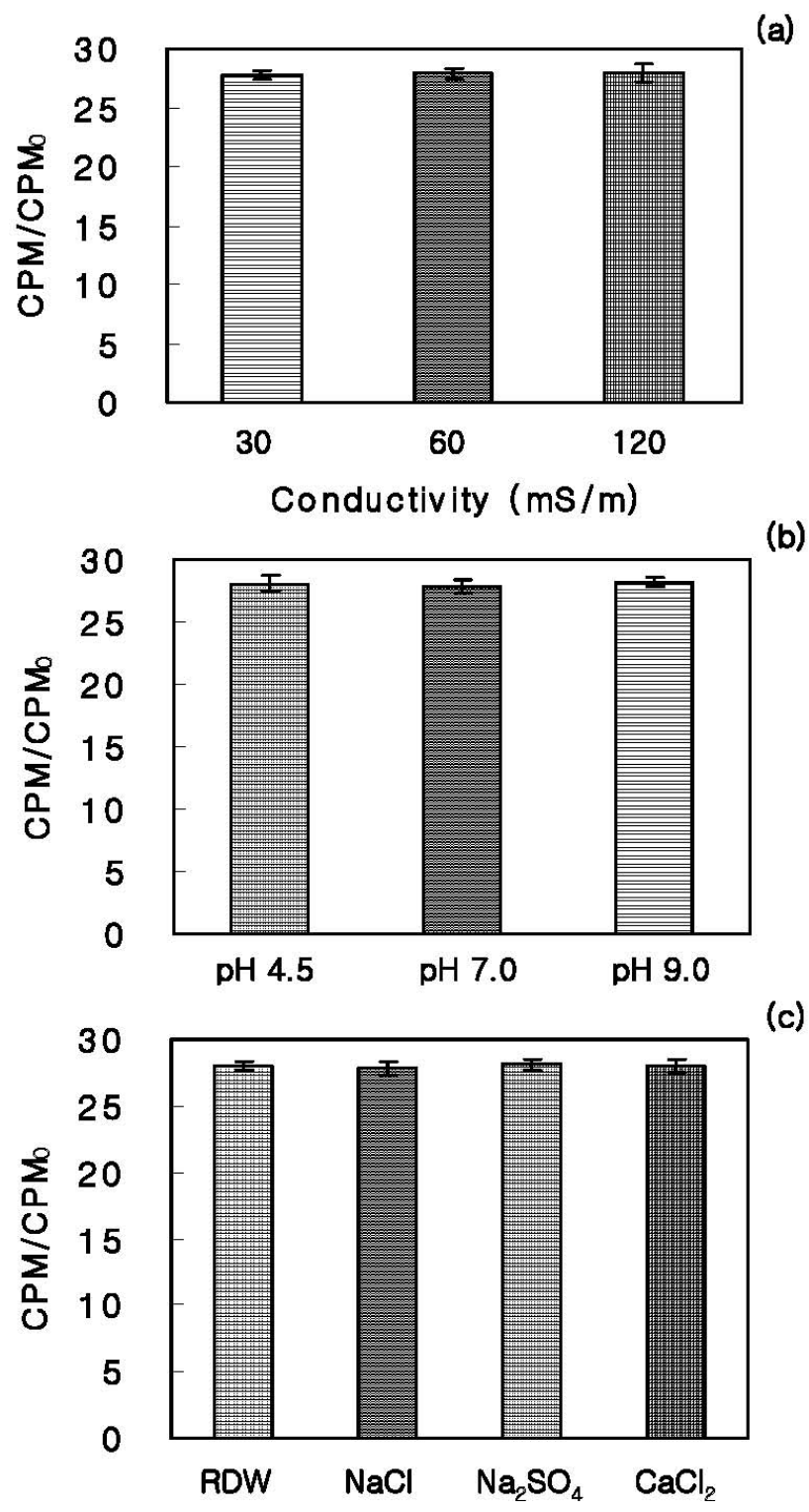

Figure 3. Dependence of scintillation intensity of the ${ }^{14} \mathrm{C}$-labeled NDMA (100 ng/L) on the (a) conductivity $(30,60$, and $120 \mathrm{mS} / \mathrm{m}$ with $\mathrm{NaCl}$ at $\mathrm{pH} 7)$, (b) $\mathrm{pH}(4.5,7$, and 9 at conductivity $60 \mathrm{mS} / \mathrm{m}$ with $\mathrm{NaCl})$, and (c) electrolyte salt type $\left(\mathrm{NaCl}, \mathrm{Na}_{2} \mathrm{SO}_{4}\right.$, and $\mathrm{CaCl}_{2}$ at $\mathrm{pH} 7$ and conductivity $60 \mathrm{mS} / \mathrm{m}$ ).

independent of ion concentration, $\mathrm{pH}$, and ion type (Black et al., 1966; Touiton and Rubinstein, 1986).

\subsection{NDMA removal by coagulation precipitation}

At the dosages employed, alum and ferric coagulants neutralized particulate surface charge and precipitate metal (hydr)oxide solids. Dissolved organic compounds can precipitate with or adsorb onto the solids. Figure 4 presents data from RDW in a control sample (no coagulant added) and after three different coagulation treatments. Error bars for the

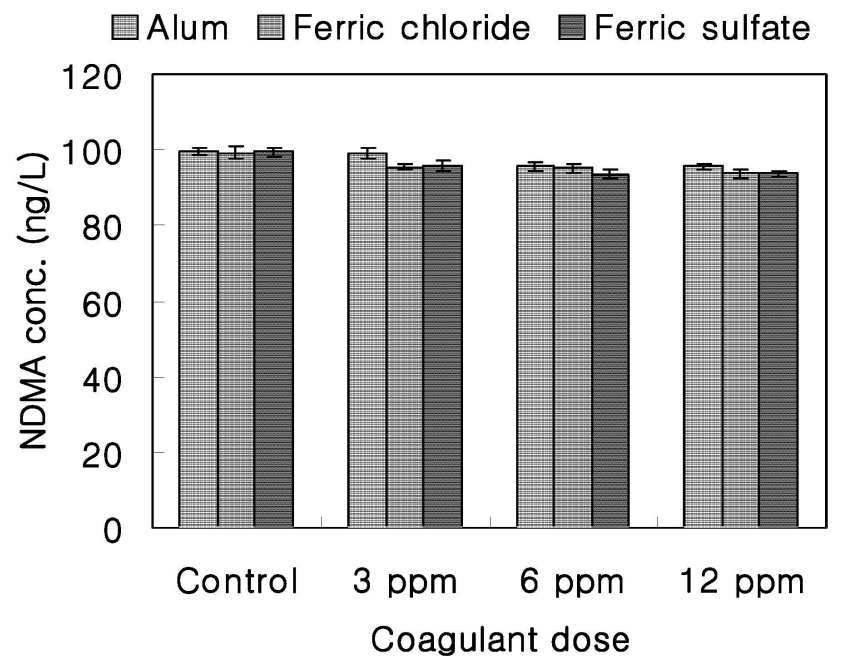

Figure 4. Effect of coagulant types on NDMA removal from RDW.

control sample indicate high reproducibility in quantifying NDMA concentrations; similar levels of reproducibility were observed throughout this study. The discussion throughout the remainder of this paper will compare percentage removal ([1-C/C $\left.\left.C_{o}\right] \times 100 \%\right)$ of NDMA to simplify the comparison between coagulants; $C_{o}$ and $C$ are NDMA concentrations in the control sample and after experiment treatment, respectively.

Three dosages $(3,6$, and $12 \mathrm{mg} / \mathrm{L})$ of each coagulant were added to RDW with NDMA at an initial concentration of $100 \mathrm{ng} / \mathrm{L}$. This initial concentration was selected such that $99 \%$ removal $(\log 2)$ of the compound could be quantified above the MDLs. In a previous study, hydrophobic micropollutants were successfully removed by the coagulants (Westerhoff et al., 2005). NDMA removal increases slightly with increasing coagulant dose for all the coagulants, although the removal was somewhat constant among those coagulants (Fig. 4). However, chemical precipitation for all coagulants achieves minimal removal $(<7 \%)$ of NDMA from the RDW, indicating that coagulation may not be a good removal mechanism for this hydrophilic compound due to the presence of polar functional groups. This is presumably because NDMA's partition onto the particulate matter is minimal due to its decreased hydrophobicity as measured by octanol-water partitioning coefficient $\left(\log K_{o w}=0.57\right)$.

\subsection{NDMA removal by PAC adsorption}

Kinetic experiments were performed by collecting samples after 1,4 , and $24 \mathrm{~h}$ of contact in the presence of PAC at concentrations ranging from 1 to $50 \mathrm{mg} / \mathrm{L}$. Representative PAC dose-response data for NDMA is shown in Fig. 5. At a $1 \mathrm{mg} / \mathrm{L}$ PAC dose, less than $6 \%$ of NDMA was removed after contact times of 1,4 , and $24 \mathrm{~h}$. Increasing PAC dose slightly improved NDMA removal (13\% to $17 \%$ ), but the effect of contact time was insignificant. Previous studies showed that 


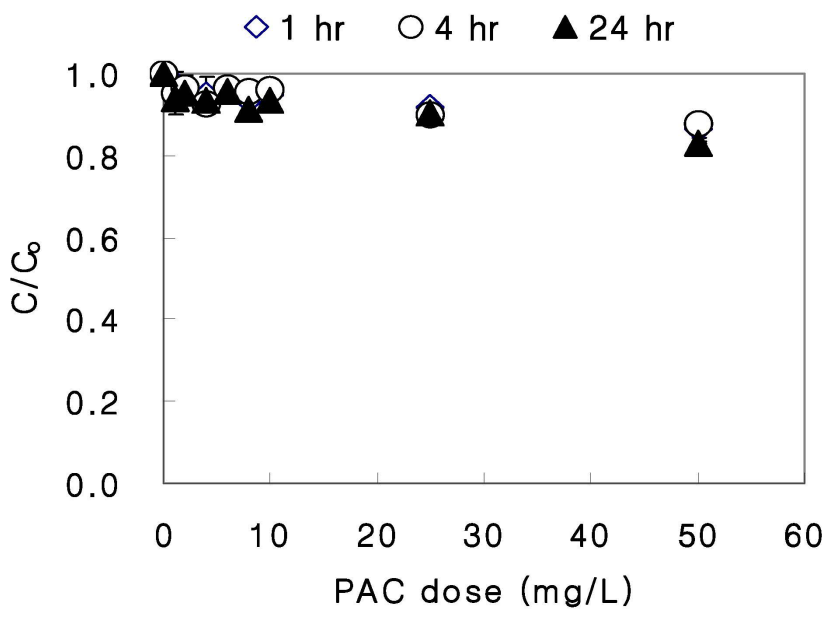

Figure 5. Effect of contact time $(1,4$, and $24 \mathrm{~h})$ on NDMA $\left(C_{o}\right.$ $=100 \mathrm{ng} / \mathrm{L})$ removal from RDW at relatively low PAC dosages $(1-$ $50 \mathrm{mg} / \mathrm{L})$

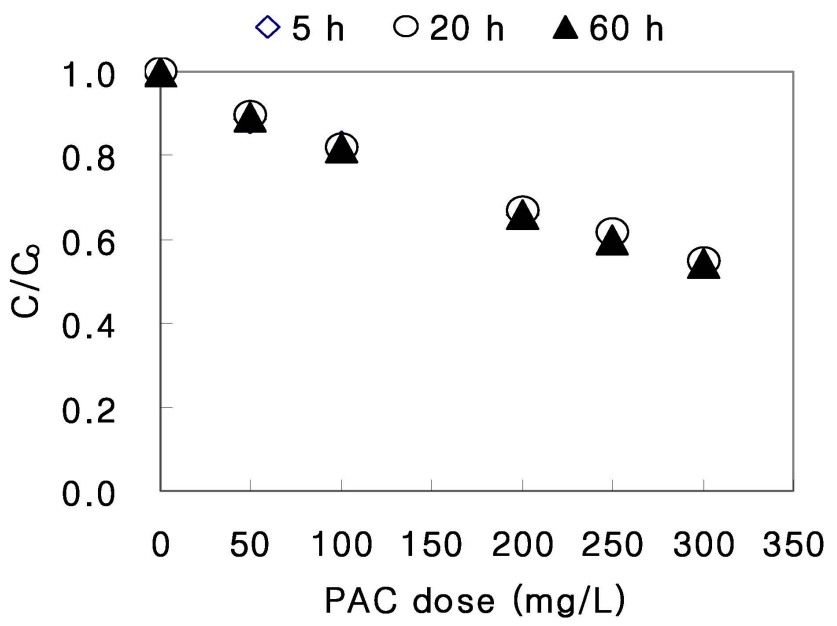

Figure 6. Effect of contact time $(5,20$, and $60 \mathrm{~h})$ on NDMA $\left(C_{o}=\right.$ $100 \mathrm{ng} / \mathrm{L})$ removal from RDW at relatively high PAC dosages (50$300 \mathrm{mg} / \mathrm{L})$.

longer contact times and higher PAC dose lead to higher removal of hydrophobic micropollutants ( $\log K_{o w}>3$ ) (Westerhoff et al., 2005; Yoon et al., 2005). However, NDMA removal was low (less than 20\%) in this study, presumably because of the lower levels of hydrophobic interaction (i.e., adsorption) between the PAC and NDMA.

To obtain higher NDMA removal by PAC, additional experiments were conducted at relatively high PAC dosages $(50-300 \mathrm{mg} / \mathrm{L})$ and longer contact times $(5,20$, and $60 \mathrm{~h})$ with RDW. Figure 6 shows the relationship between PAC dose and NDMA response. At a dosage of $300 \mathrm{mg} / \mathrm{L} \mathrm{PAC}$, $45 \%$ of NDMA was removed after contact times of 5,20 , and $60 \mathrm{~h}$, respectively. Increasing PAC dosage improved NDMA removal, and the effect of contact time became insignificant.
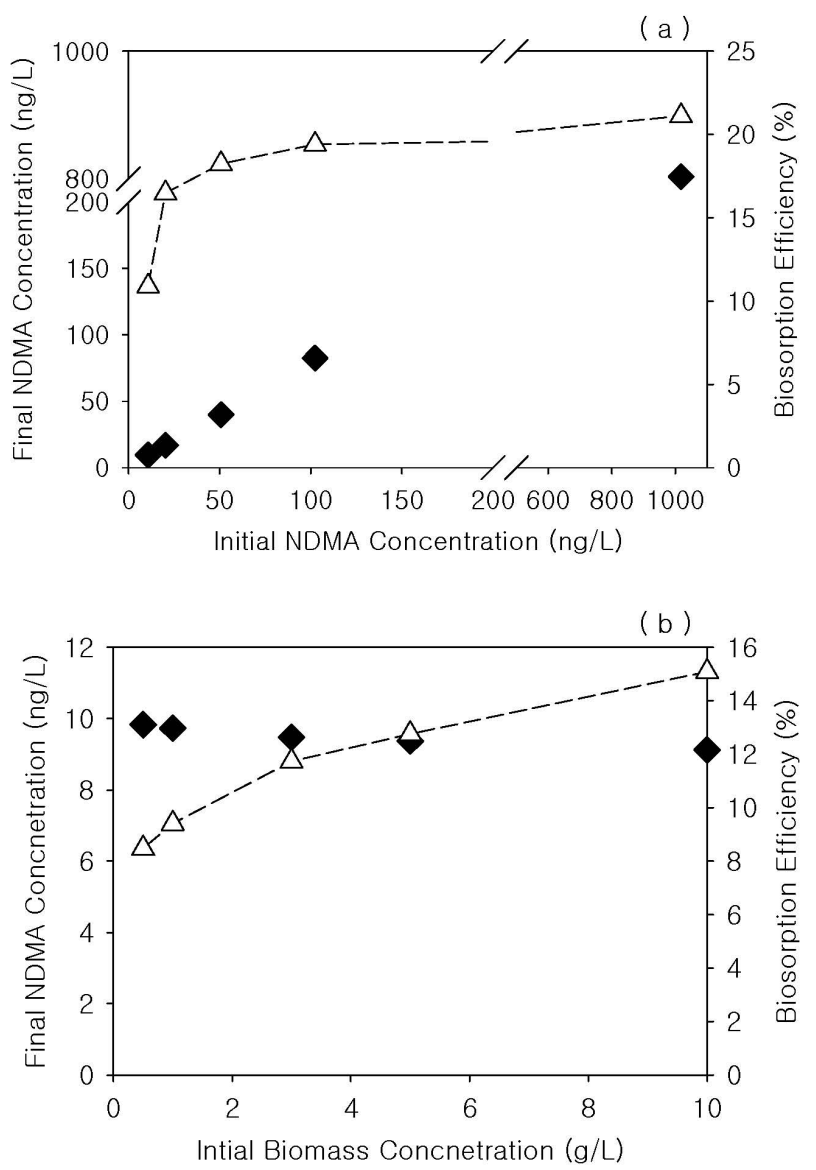

Figure 7. Effect of initial NDMA concentration $(10-1000 \mathrm{ng} / \mathrm{L})$ and biomass concentration $(0.5-10.0 \mathrm{~g} / \mathrm{L})$ in biosorption experiment. $(\checkmark$ : NDMA final concentration $(\mathrm{ng} / \mathrm{L}) ; \triangle$ : biosorption efficiency $(\%))$.

These results indicate that hydrophilic NDMA can still be removed at high PAC dosage in the presence of natural organic matter.

\subsection{NDMA removal by biosorption}

Experiments evaluating the influence of initial NDMA concentration on the removal of NDMA by biosorption at fixed values of $\mathrm{pH}$ and biomass concentration $(7.0$ and $5.0 \mathrm{~g} / \mathrm{L}$ ) were carried out. The objective of these experiments was to observe the effect of different parameters on the rate of biosorption (Fig. 4a). As shown in Fig. 7a, an increase of initial NDMA concentration increased the biosorption efficiency up to $20 \%$, implying that even concentrated biomass could not absorb the NDMA significantly. Experiments evaluating the influence of biomass concentration on the process of NDMA removal by biosorption were also carried out. The objective of these experimentswas to observe the effect of biomass concentration on the rate of biosorption. The results obtained are shown in Fig. 7b. With an initial concentration 
of $10 \mathrm{ng} / \mathrm{L}$ of NDMA, little change was observed in the biosorption efficiency of 0.5 to $10 \mathrm{~g} / \mathrm{L}$ of biomass, implying that biomass concentration does not significantly affect biosorption efficiency.

\section{Conclusions}

- Scintillation spectroscopy proved to be a simple and useful tool for quantifying radio-labeled ${ }^{14} \mathrm{C}$-labeled $N$ nitrosodimethylamine at low levels of concentration. MDLs were $0.91,0.98,1.23$, and $1.45 \mathrm{ng} / \mathrm{L}$ of NDMA with sample to scintillation liquid ratios of 10:10, 5:15, 15:5, and 2.5:17.5 respectively, without preconcentration. These low detection limits properly define a concentration range for lab process experiments because they represent a realistic range of NDMA concentrations in contaminated natural water. Scintillation intensity increases with increasing sample to scintillation liquid ratio (i.e., sample concentration) ranging from 2.5:17.5 to 10:10, while scintillation intensity decreases significantly at a higher ratio (i.e., 15:5).

- Alum, ferric chloride, and ferric sulfate coagulants removed less than $10 \%$ of NDMA. This is presumably because NDMA's partition onto the particulate matter is minimal. Addition of $10 \mathrm{mg} / \mathrm{L}$ of PAC with a $4 \mathrm{~h}$ contact time removed less than 5\%. This was also because low levels of hydrophobic interaction between PAC and NDMA occurred. However, higher PAC dosages improved NDMA removal.

- In addition, it was observed that the removal of NDMA by biosorption was insignificant at the limited conditions, indicating that biosorption may be an ineffective mechanism for removing hydrophilic NDMA even at an extremely low initial concentration (100 ng/L).

Acknowledgements. The authors would like to thank the Taeyoung Company and Brain Korea 21 of Hanyang University for financial support, and would also like to thank the Department of Life Science at Hanyang University for the analytical equipment used in this study.

Edited by: Jaeweon Cho

\section{References}

Behymer, T. D., Bellar, J. S., Ho, J. S., and Budde, W. L.: Methods for the determination of organic compounds in drinking water, US Environmental Protection Agency, Supplement II; Revision 1.1, Cincinnati, OH, 1993.

Black, A. P., Birkner, F. B., and Morgan, J. J.: The effect of polymer adsorption on the electrokinetic stability of dilute clay suspensions, J. Colloid Interf. Sci., 21, 626-648, 1966.

CFR: Code of Federal Regulations, Title 40, Chapter 1, Part 131.36., 1 July edn., 2001.
Chemfinder: $N$-nitrosodimethylamine [62-75-9] database, Cambridge, UK, CambridgeSoft, 2003.

DHS: California Department of Health Services, NDMA in California Drinking Water, 15 March 2002.

Eaton, A. and Briggs, M.: NDMA-analysis of a new DBP, AWWA Water Quality Conference Proceedings, Salt Lake City, Utah, 2000.

Fleming, E. C., Pennington, J. C., Wachob, B. G., Howe, R. A., and Hill, D. O.: Removal of $N$-nitrosodimethylamine from waters using physical-chemical techniques, J. Hazard. Mater., 51, 151164, 1996.

Gumnison, D., Zappi, M. E., Teeter, C., Pennington, J. C., Baipai, R., and Attenuation, R.: Mechanism of $N$-nitrosodimethylamine by an operating intercept and treat groundwater remediation system, J. Hazard. Mater., 73, 179-197, 2000.

Holgnè, J. and Bader, H.: Rate constants of reactions of ozone with organic and inorganic compounds in water II: Dissociating organic compounds, Water Res., 17, 185-194, 1983.

Jungbauer, A.: Adsorption isotherms of 17 beta-estradiol on granular activated carbon (GAC), Chemosphere, 44, 1573-1579, 2001.

Kaplan, D. L. and Kaplan, A. M.: Biodegradation of $N$ nitrosodimethylamine in aqueous and soil systems, Appl. Environ. Microb., 50, 1077-1086, 1985.

Leoppky, R. N. and Micheljda, C. J.: Nitrosamines and related $N$-nitroso compounds: chemistry and biochemistry, American Chemical Society, Washington, DC, 1994.

Mitch, W. A. and Sedlak, D. L.: Characterization and fate of $\mathrm{N}$ Nitrosodimethylamine precursors in municipal wastewater treatment plant, Environ. Sci. Technol., 38, 1445-1454, 2004.

Mitch, W. A., Sharp, J. O., Trussell, R. R., Valentine, R. L., AlvarezCohen, L., and Sedlak, D. L.: $N$-nitrosodimethylamine (NDMA) as a drinking water contaminant: a review, Environ. Eng. Sci., 20, 389-404, 2003.

MOE: Ontario Ministry of the Environment and Energy, Regulation Made Under the Ontario Water Resources Act: Drinking Water Protection - Larger Water Works, 26 August 2000.

NRC: National Research Council, NTIS Document PB82-182890, 1981.

Perrin, D. D. and Dempsey, B.: Buffers for $\mathrm{pH}$ and metal ion control, Chapman and Hall, London, 1974.

Shen, Y.: Determination of $N$-nitrosodimethylamine at part per trillion levels using positive chemical ionization from aqueous samples, AWWA Water Quality Conference Proceedings, Salt Lake City, Utah, 2000.

Siddiqui, M. and Atasi, K.: NDMA occurrence and formation - a review, Proceedings of Annual AWWA Conference, Washington, DC, 2001.

Touitou, E. and Rubinstein, A.: Targeted enteral delivery of insulin to rats, Int. J. Pharm., 30, 95-99, 1986.

Westerhoff, P., Yoon, Y., Snyder, S., and Wert, E.: Fate of endocrine disruptor, pharmaceutical, and personal care chemicals during simulated drinking water treatment processes, Environ. Sci. Technol., 39, 6649-6663, 2005.

Yoon, Y., Westerhoff, P., and Snyder, S.: Adsorption of ${ }^{3} \mathrm{H}$-labeled 17-estradiol on powdered activated carbon, Wat. Air Soil Pollut., 166, 343-351, 2005. 